\section{The effects of temporal variables on the acquisition of human avoidance behavior}

\author{
FRANK D. MILLER, RICHARD S. KALIN, and PHILIP A. MEYER* \\ University of South Dakofa, Vermillion, S. Dak. 57069
}

Human Ss were given avoidance training employing a blast of pressurized air directly behind the ear as the noxious stimulus, a button depression as the avoidance response, and a light as the warning signal. In this experiment, signal duration and trace interval were factorially manipulated in a manner that also permitted interstimulus interval comparisons. The most striking effect of these temporal variables was on avoidance latency, where longer latencies were associated with longer ISIs. Resistance to extinction appeared quite strong, and the suddenness of conditioning resembled all-or-none learning. The similarity of these results to previous findings and their significance were discussed.

This experiment concerns several temporal variables involved in the presentation of a signal prior to the occurrence of a noxious stimulus (NS) in the discriminated avoidance paradigm. Both the duration of the signal and the trace interval, or time between signal offset and scheduled onset of the NS, are manipulable in this paradigm. Typically, the combination of these two intervals is referred to as the interstimulus interval (ISI). In a delay conditioning procedure, the trace interval is zero, while signal duration and ISI are equal. However, the typical practice of terminating the signal when a successful avoidance response $(\mathrm{Ra})$ occurs disturbs the temporal relations just discussed. When an $S$ avoids reliably, signal duration is no longer under $E$ control and may be substantially reduced. Moreover, if no NS is presented (as on avoidance trials), duration of the trace interval is, perhaps, functionally altered. One conceivable result of the signal-termination procedure might be the elimination of any effects of varying signal duration. Furthermore, differences between delay and trace conditioning procedures could, likewise, be negligible, since on avoidance trials a "trace" interval of sorts is presented even with the delay condition.

Despite these concerns, a number of stridies have shown effects of ISI under buth delay and trace conditions. With the delay procedure, a number of studies have supported the relationship that better acquisition of avoidance occurs under longer ISI (cf. Beecroft, 1967; Bolles, 1967, pp. 409.411). However, Kimble, Mann, \& Dufort (1955) have reported poorer performance in human eyelid avoidance as ISIs increased from 500 to 1,500 msec. Similarly, Black (1963) has found an inverse relationship between

\footnotetext{
*Requests for reprints should be sent to Philip A. Meyer. Department of Psychology, University of South Dakota. Vermillion, S. Dak. 57069.
}

shuttlebox avoidance with rats and ISIs from 10 to $30 \mathrm{sec}$. Employing a trace procedure in the shuttlebox with dogs, Kamin (1954) has also reported poorer avoidance with increased ISIs from 5 to $40 \mathrm{sec}$. However, Pearl \& Edwards (1963) have shown improved performance of leverpress avoidance by rats with trace intervals of 19 to $59 \mathrm{sec}$, as compared to a 4-sec interval.

Along with these varied results, a general finding with avoidance behavior is that the delay procedure leads to superior performance in comparison to the trace procedure (e.g., Black, 1963). In the typical trace procedure, the signal is presented for a brief period, normally too short a time for a $\mathrm{Ra}$ to occur during the signal. Hence, the signal-termination aspect found in the delay procedure is absent in the traditional trace avoidance condition. However, the signal duration also differs in these delay vs trace comparisons. The question arises as to whether the decrement in avoidance performance found with the trace procedure may be solely at tributable to the lack of response-produced signal termination (Bolles \& Grossen, 1969) or, in part, to the shorter signal duration (Brush, 1957). Considering both the somewhat varied results obtained for ISI and the ambiguity regarding the delay vs trace comparisons, a determination of these temporal relations for this technique with human Ss seemed desirable.

Thus, the present study was designed to manipulate both signal duration $(2,5$, and $8 \mathrm{sec}$ ) and trace interval (including a delay conditioning procedure, 0,3 , and $6 \mathrm{sec}$ ) on nonavoidance trials in a 3 by 3 factorial design. Since the shortest signal duration was $2 \mathrm{sec}$, there was ample opportunity for a $\mathrm{Ra}$ to occur and terminate the signal on avoidance trials. A further feature of the present study was the availability of ISI comparisons within the factorial.

$$
\text { SUBJECTS }
$$

The Ss were 90 undergraduate students enrolled in an introductory psychology course at the University of South Dakota. Twelve additional Ss were eliminated from the experiment; six failed to follow instructions and six others had prior knowledge of the experiment.

APPARATUS

The apparatus used has been described in detail in a previous study (Miller, Kalin, Eckenroth, \& Meyer, 1970). Briefly, it consists of a response button mounted on the right arm of a dental chair with headrest in which $S$ was seated and an air-delivery system capable of delivering a blast of pressurized air to the mastoid portion of the temporal bone behind S's right ear. A $7 \frac{1}{2}$-W white signal light was mounted on a wall in front of S's head. The circuitry necessary for presentation of stimuli, timing of intervals, and recording response latency was provided by relay switches, Hunter interval timers, and a Hunter Klockounter. Additional equipment included an earplug for $S$ 's right ear, an ace bandage which was tied around S's forehead and the headrest, and a mirror that allowed $E$ to observe $S$ continuously. PROCEDURE

Each $S$ was seated in the chair and given a typewritten card of instructions which read: "Read these instructions slowly and carefully. I am not allowed to give you any additional information, so please do not ask me any questions. Place the earplug located on the arm of the chair in your right ear and rest your head on the headrest. THERE IS A RESPONSE YOU MAY MAKE TO CONTROL WHAT HAPPENS TO YOU IN THIS EXPERIMENT. When you have finished reading these instructions, retum this card to me. I will then attach a strap around your head. Try to keep your head in the same position throughout the course of the experiment." The nozzle was positioned so that the air blast, which served as the NS, struck $S$ on the mastoid portion of the temporal bone, $1 / 2 \mathrm{in}$. behind the crevice separating the bone and right pinna. The distance between the end of the nozzle and the bone was $1 / 2 \mathrm{in}$. With reference to the vertical plane, the air nozzle was positioned midway between the upper and lower edges of the pinna and aligned to form a 45-deg angle with the side of S's head.

Signal durations of 2,5 , and $8 \mathrm{sec}$ were factorially varied with trace interval $(0,3$, and $6 \mathrm{sec}$ ) in a 3 by 3 design, for which five males and five females were assigned randomly to each of the nine groups. The groups are designated by two digits, separated by a hyphen, representing the signal-duration and trace-interval conditions, respectively, for that group. The sum of the two digits designates the ISI for that group. In this factorial design several ISI comparisons are possible after 
Table 1

Nean Trials to Criterion. Hean Number of Avoidance Responses, and Number of $S_{s}$ Conditioning During Acquisition as a Function of Trace Interval and Signal Duration in Seconds

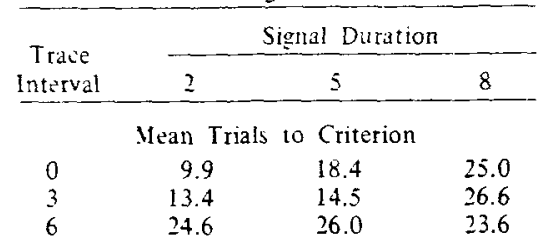

Mean Number of Aroidance Responses

$\begin{array}{llll}0 & 32.7 & 24.6 & 18.2 \\ 3 & 26.7 & 28.0 & 16.7 \\ 6 & 18.5 & 17.3 & 20.7\end{array}$

Number of $\$ s$ Conditioning

\begin{tabular}{rrrr}
0 & 9 & 7 & 5 \\
3 & 0 & 8 & 5 \\
6 & 6 & 6 & 6 \\
\hline
\end{tabular}

grouping conditions with equivalent ISIs together. For example, Groups 8-0, 5.3, and 2-6 all have ISIs of $8 \mathrm{sec}$, while Groups 5.0 and 2.3 have ISIs of 5 sec.

All Ss were administered 40 avoidance-only acquisition trials according to the experimental condition to which they were assigned. Each trial began with signal onset and, following the prescribed ISI, a 40-psi air blast was presented for $6 \mathrm{sec}$. Note that signal offset under the 3 and 6-sec trace conditions occurred before the end of the ISI. A Ra was defined as a depression of the response button during the ISI. A Ra prevented onset of the NS and, if still present; immediately terminated the signal. A button depression during the NS did not terminate it. The intertrial interval (ITI) from NS offset to signal onset for the next trial was $5 \mathrm{sec}$. The time periods for the occurrence of the signal, NS, and ITI were included on all trials, regardless of whether or not $S$ responded.

Immediately following acquisition trials, all $\mathrm{Ss}$ received 40 extinction trials on which the signal duration, trace interval, and ITI were programmed as in acquisition. During extinction, no NS presentations occurred. Each $S$ was then required to fill out an 18-item questionnaire which provided information about possible prior knowledge of the study, reaction to the air blast, awareness of the relationship between the light and the air blast, and other such matters.

\section{RESULTS}

Mean number of trials to a three-successive-responses criterion (TC3), mean number of Ras, and number of Ss reaching criterion are given in Table 1 for each group. The signal-duration and trace-interval main effects were each evaluated by combining data from the appropriate groups and performing
Kruskal.Wallis analyses. In the case of both TC 3 and number of Ras. neither main effect was significant, $\mathrm{p}>.10$. With the delay groups (2-0. 5-0, and 8-0), however, avoidance performance was inversely related to signal duration. Thus, a Kruskal-Wallis analysis of the TC 3 data for the delay groups yielded a significant simple effect of signal duration, $\mathrm{H}^{\prime}(2)=6.04, \mathrm{p}<.05$.

In contrast to the previous data, latency of Ras proved to be a more sensitive measure of avoidance performance. Average latency of Ras for each $S$ who conditioned was computed. Group mean latency for the three signal-duration conditions are presented in Fig. $I$ as a function of trace interval. As may be seen from Fig. 1, group mean latency tended to increase with longer trace intervals. Similarly, latencies tended to be shortest with the 2-sec signal duration. Both of these main effects, trace interval and signal duration, were evaluated by combining data from the appropriate groups and performing Kruskal-Wallis analyses. Significant effects occurred for both trace interval, $\mathrm{H}^{\prime}(2)=7.60, \mathrm{p}<.025$, and signal duration, $\mathrm{H}^{\prime}(2)=6.00, \mathrm{p}<.05$. Similar analyses were also performed on the latency data from only the last 10 training trials (31-40). Again, significant effects in the same directions occurred for both trace interval, $\mathrm{H}^{\prime}(2)=7.77, \mathrm{p}<.025$, and signal duration, $H^{\prime}(2)=6.74, p<.05$.

In order to examine ISI in the present design, groups with equal ISIs were combined, thus providing five groups with
ISIs of 2, 5,8,11, and 14 sec. respectively. The $\mathrm{TC} 3$ and mean number of Ras data suggest a decrease in pertormance from the 2 - to the 11-sec groups with a slight reversal at the 14-sec group: however. analyses of both measures rere nonsignificant. $\mathrm{H}^{\prime} \mathrm{s}(4)=6.88$ and 7.13 . respectively. $\mathrm{p}<20$. An identical trend appeared in the regrouped latency data of Fig. I which was significant, $H^{\prime} s(4)=11.30 . p<.025$. The mean latencies (in seconds) for the five ISI groups, in order of increasing ISI, were $0.39,0.83,1.05,4.32$, and 2.09 .

With respect to rate of acquisition, 32 of the $61 \mathrm{Ss}$ who conditioned did so in one trial. Having made a first response, these $\mathrm{Ss}$ continued to respond on all of the following acquisition trials. An efficiency score was calculated for each $S$ who conditioned. This score consisted of taking the total number of Ras minus one and dividing the remainder by the number of acquisition trials remaining after the first $\mathrm{Ra}$. This quotient was then multiplied by 100. These group mean efficiency scores were high, ranging from $89 \%$ to $99 \%$, with an overall group mean of $94.5 \%$.

During the extinction period of 40 trials, only 11 of the 61 Ss who had conditioned met an extinction criterion of five successive nonresponses. In only two of the nine groups was there more than one $S$ who extinguished, and in no group did more than three Ss extinguish.

\section{DISCUSSION}

No overall effect of signal duration or

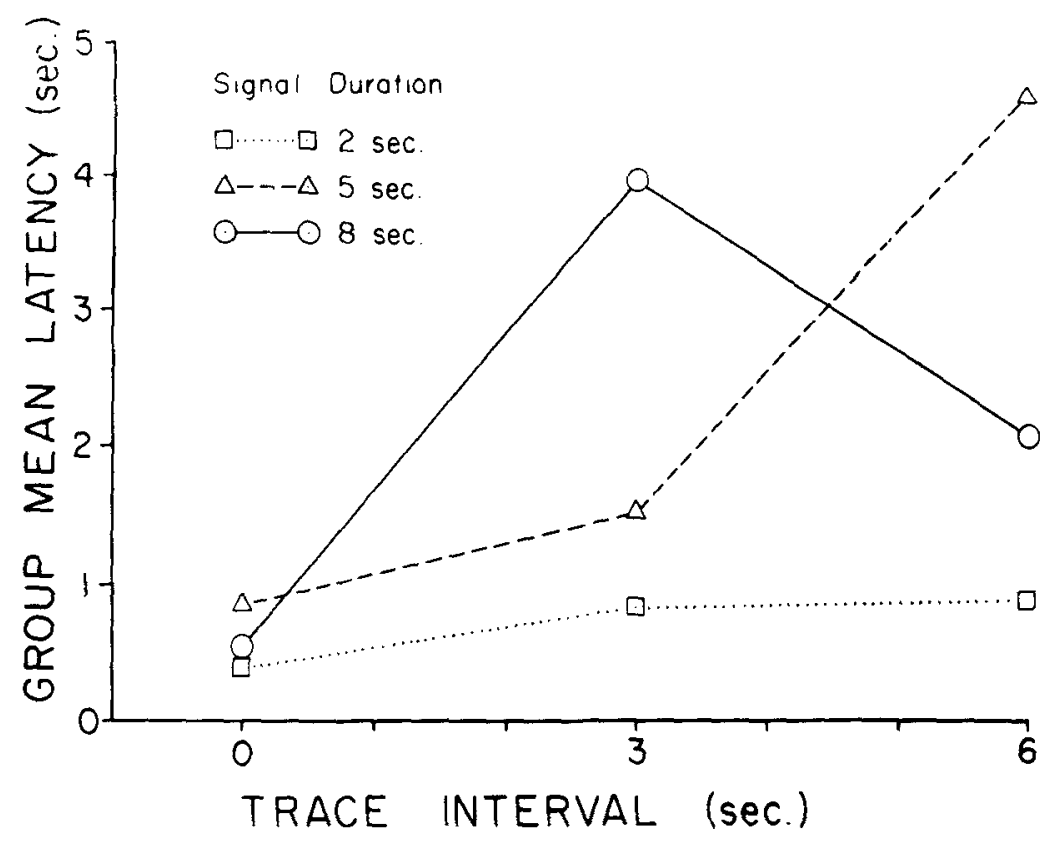

Fig. 1. Group mean latency as a function of trace interval for the three signal-duration conditions. 
trace interval was obtained for either TC 3 or number of Ras. However, within the design. the TC3 data indicated faster acquisition with shorter signals (and ISIs) for the delay groups. This finding appeurs consistent with those interpretations which invoke the laws of classical conditionng to account for temporal effects of associating the signal and the aversive stimulus (e.g., Mowrer. 1960). Also noteworthy in this regard are the recent findings of Perlmuter, Funk, Taylor, \& Kimble (1969) that voluntary instructed responding was inversely related to ISI.

In the present study, avoidance latency proved more sensitive than the indices of avoidance behavior just discussed. Avoidance latency was directly related to ISI. In general, as ISIs increased, either by increasing signal duration or trace interval, longer avoidance latencies occurred. If latency is regarded as indicating strength of conditioning, then stronger conditioning occurred with shorter ISI. Furthermore, the shortest latencies were associated with the delay procedure. Apparently, the delay procedure leads to stronger conditioning than does the trace procedure, even when ample opportunity is given for response-produced signal termination. However, an analysis of different avoidance latencies on the basis of response shaping (Prokasy, 1965) suggests that longer latencies are more frequently reinforced with longer ISIs. Regardless of interpretive mode, the present latency data are strikingly similar to those reported by Behrend \& Bitterman (1962, 1964) with fish.

Also of interest, Ss typically acquired the $\mathrm{Ra}$ in a fashion resembling one-trial learning. In addition, Ss usually failed to extinguish having once acquired the $\mathrm{Ra}$. These aspects of the present results are consistent with other findings from our laboratory (Meyer, in press; Miller, Kalin, Eckenroth, \& Meyer, 1970). REFERENCES

BEECROFT, R. S. Emotional conditioning. Psychonomic Monograph Supplements. 1967. 2, 45-72.

BEHREND, E. R., \& BITTERMAN. M. E. $h$ : oidance conditioning in the goldfish: Exploratory studies of the CS-US interval. American Journal of Psychology, 1962, 75, 18-34.

BEHREND, E. R., \& BITTERMAN, M. E. Avoidance conditioning in the fish: Further studies of the CS.US interval. American Journal of Psychology, 1964, 77, 15-28.

BLACK, A. H. The effect of CS-US interval on avoidance conditioning in the rat. Canadian Journal of Psychology, 1963, 17, 174-182.

BOLLES, R. C. Theory of motivation. New York: Harper \& Row, 1967.

BOLLES, R. C., \& GROSSEN, N. E. Effects of an informational stimulus on the acruisition of avoidance behavior in rats. Journal of Comparative \& Physiological Psychology, $1969.68,90-99$

BRUSH, E. S. Traumatic avoidance learning: The effects of conditioned stimulus length in a frec-responding situation. Joumal of Comparative \& Physiological Psychology, $1957,50.541-546$

KAlIIN. L. J. Traumatic avoidance learning: The iffects of CS-LCS interval with a trace conditioning procedure. Journal of Comparative \& Physiological Psychology, $1954.47 .65-72$.

KIMBLE. G. A.. MANN, L. I., \& DUFORT, R. H. Classical and instrumental eyelid conditioning. Journal of Experimental Psychology, 1955, 49. 407-417.

MEYER, P. A. The sole of an unavoidability procedure in eliminating avoidance behavior with humans. Journal of Experimental Psychology, in press.

MILLER, F. D., KALIN, R. S., ECKENROTH,

W. N., \& MFYER, P. A. Acquisition variables

in human avoidance behavior. Psvchonomic Science, 1970, 21, 233-35.

MOWRER. O. H. Learning theor and behatior. Veu York: Wiley, 1970.

PHARL, J., \& EDWARDS, R. E. CS-LS interal in the trace conditioning of an avoidance response. Psychological Reports, 1963, 13. 43.45.

PERLMUTER, L. C., HLNK. A. M., TAYLOR $G$. A., \& KIMBLE, G. A. Effect of interstimulus interval on conditioning of voluntary instructed resnonses. Journal of Experimental Psychology, 1969, 79, 403-405. PROKASY, W. F. Classical eyelid conditioning: Experimenter operations, task demands, and response shaping. In W. 1. Prokasy (Ed.), Classical conditioning: $A$ symposium. New York: Appleton-Century-Crofts, 1965. Pp. 208-225.

\title{
Cognitive style in the organization and articulation of ambiguous stimuli
}

\author{
SAMUEL F. MOORE, ${ }^{*}$ GOLDINE C. GLESER, and JOEL S. WARM \\ University of Cincinnati, Cincinnati, Ohio 45221
}

This investigation assessed the relation between the abilities to organize and articulate ambiguous stimuli and the global-analytic continuum of cognitive style postulated by Witkin in his theory of psychological differentiatjon (Witkin et al, 1962). Thirty-five Ss served in the study. Cognitive style was measured by the rod and frame test; the Obscure Figures Test (OFT) was used to measure organizing or structuring ability. Articulation was operationally defined in terms of memory for the OFT figures as indexed by recognition and identification measures. Consistent with predictions from Witkin's theory, significant correlations were obtained between cognitive style and the abilities of organization and articulation.

Witkin's theory of psychological differentiation (Witkin et al, 1962) attempts to deal with individual differences in information processing, i.e., cognitive style. The theory proposes a continuum of cognitive style characterized by global and analytic polarities. According to the theory, individuals located at the analytic pole are superior to those at the global pole in analyzing, organizing, and articulating their experiences.

Analysis refers to the classic dimension of field dependence, field independence; global individuals are field dependent, while analytic individuals are field independent. According to Witkin, those with an analytic cognitive style are more able to attend to relevant aspects of stimulation-are less susceptible to confounding contextual cues-than are those with a more global cognitive style. To date, an impressive array of evidence is available to support this notion across a variety of situations involving perceptual, social, and intellectual functions (see reviews by Dember, 1960; Moore, 1969; Witkin, 1964). By contrast, evidence regarding the dimensions of organization

*Now at Community Vental Health Clinic, Lawrenceburg. Indiana 47025. and articulation is equivocal.

As used by Witkin, organization refers to the ability to structure ambiguous or poorly organized stimuli, while articulation refers essentially to the degree of clarity in recollection of experiences. Several studies, using Rorschach cards as ambiguous stimuli, have demonstrated a significant relation between the degree of analytic ability and organization (Hertzman in Witkin et al, 1954; Phillips, 1957; Witkin et al, 1962). However, these results have not been replicated when other techniques were used (Witkin et al, 1962). Similarly, a number of experiments, using memory for form and retroactive inhibition paradigms, have been performed to assess Witkin's notion of articulation, but with inconclusive results (Gardner \& Long, 1961; Gollin \& Baron, 1954; Witkin et al, 1962).

The present investigation was designed to provide a further test of the theory of psychological differentiation with respect to the abilities of organization and articulation. The Obscure Figures Test (OFT), an instrument which employs simple line drawings to measure S's innovativeness in imposing organization on ambiguous stimuli (Acker \& McReynolds, 1965; McReynolds \& Acker, 1965) was

Psychon. Sci., 1970, Vol. 21 (4) 